\title{
Distinct Fibroblast Growth Factor (FGF)/FGF Receptor Signaling Pairs Initiate Diverse Cellular Responses in the Oligodendrocyte Lineage
}

\author{
Dale Fortin, ${ }^{1}$ Eran Rom, ${ }^{2}$ Haijun Sun, ${ }^{3}$ Avner Yayon, ${ }^{2}$ and Rashmi Bansal ${ }^{1}$ \\ ${ }^{1}$ Department of Neuroscience, University of Connecticut Medical School, Farmington, Connecticut 06030, 2ProChon Biotech Ltd., Rehovot, Israel 76114, \\ and ${ }^{3}$ ImClone Systems Inc., New York, New York 10014
}

\begin{abstract}
Fibroblast growth factors (FGFs) have been implicated in numerous cellular processes, including proliferation, migration, differentiation, and survival. Whereas FGF-2, the prototypic ligand in a family of 22 members, activates all four tyrosine kinase FGF receptors (FGFR1-FGFR4), other members demonstrate a higher degree of selectivity. Oligodendrocytes (OLs), the myelin-producing cells of the CNS, are highly influenced by FGF-2 at all stages of their development. However, how other FGFs and their cognate receptors orchestrate the development of OLs is essentially undefined. Using a combination of specific FGF ligands and receptor blocking antibodies, we now show that FGF-8 and FGF-17 target OL progenitors, inhibiting their terminal differentiation via the activation of FGFR3, whereas FGF-9 specifically targets differentiated OLs, triggering increases in process growth via FGFR2 signaling; FGF-18 targets both OL progenitors and OLs via activation of both FGFR2 and FGFR3. These events are highly correlated with changes in FGF receptor expression from FGFR3 to FGFR2 as OL progenitors differentiate into mature OLs. In addition, we demonstrate that, although activation of FGFR1 by FGF-2 leads to proliferation of OL progenitors, it produces deleterious effects on differentiated OLs (i.e., aberrant reentry into cell cycle and downregulation of myelin proteins with a loss of myelin membrane). These data suggest that ligand availability, coupled with changes in FGF receptor expression, yield a changing repertoire of ligand-receptor signaling complexes that contribute critically to the regulation of both normal OL development and potential OL/myelin pathogenesis.
\end{abstract}

Key words: oligodendrocyte; myelin; FGF-2; FGF-8; FGF-9; fibroblast growth factor

\section{Introduction}

Oligodendrocytes (OLs), the myelin-producing cells of the CNS, are critical in establishing and maintaining the speed and efficacy of electrical impulses along axons. Inadequate myelination or damage to myelin as occurs in multiple sclerosis leads to severe neurological deficits. Understanding environmental signals involved in OL development may provide insights into the prevention and treatment of myelin disorders.

OL progenitors arise from localized regions of the embryonic ventral ventricular zone. They then migrate away to populate different regions, proliferate, and differentiate into myelinproducing cells, progressing along a well characterized developmental pathway that is highly correlated in vitro and in vivo (Pfeiffer et al., 1993; Warrington et al., 1993; Miller, 2002). OL

\footnotetext{
Received April 20, 2005; accepted June 26, 2005.

This work was supported by National Institutes of Health Grant NS 38878. We thank Dr. C. A. MacArthur (Washington University School of Medicine, St. Louis, M0) for the gift of FGF-8, Pfizer Global Research and Development (Ann Arbor, MI) for PD173074, ImClone Systems Inc. (New York, NY) for anti-FGFR1, and ProChon Biotech (Rehovot Israel) for anti-FGFR2 and FGFR3 blocking antibodies. We are pleased to acknowledge the contributions by $S$. Winkler for cell culture and Melissa Bryant and Adam Denninger for immunoblot analysis. We thank Drs. S. E.Pfeiffer, C. Marta, M. Rasband, and M. Anitei (University of Connecticut Medical School, Farmington, CT) for their insightful comments.

Correspondence should be addressed to Dr. Rashmi Bansal, Department of Neuroscience, University of Connecticut Medical School, 263 Farmington Avenue, Farmington, CT 06030-3401. E-mail: bansa@@neuron.uchc.edu. D0I:10.1523/JNEUROSCI.2120-05.2005

Copyright $\odot 2005$ Society for Neuroscience $\quad$ 0270-6474/05/257470-10\$15.00/0
}

maturation is regulated by a variety of growth factors, including fibroblast growth factors (FGFs) (for review, see Bansal, 2002). For example, FGF-2 stimulates OL progenitor proliferation and migration and inhibits terminal differentiation. Postmitotic, mature OLs also respond to FGF-2, resulting in increased process elongation. In addition, FGF-2 also induces cell cycle reentry and myelin protein downregulation with a loss of myelin membranes (Grinspan et al., 1993; Fressinaud et al., 1995; Bansal and Pfeiffer, 1997), events likely to reflect pathological processes associated with demyelinating diseases (Bansal, 2002).

At least 18 different FGFs are expressed in a temporally and spatially regulated manner in the brain (Ford-Perriss et al., 2001), including regions in which OL progenitors originate, migrate, or differentiate. For example, FGF-2 and FGF-8 (and its related subfamily members FGF-17 and FGF-18) are most robustly expressed during embryonic development, whereas FGF-9 is expressed in the postnatal and adult brain, including the white matter (Nakamura et al., 1999; Xu et al., 1999, 2000; Ford-Perriss et al., 2001; Tanaka et al., 2001; Garel et al., 2003; Storm et al., 2003; Hasegawa et al., 2004; Itoh and Ornitz, 2004). Much of the information on FGF signaling in OLs has evolved from the application of FGF-2, which activates all FGF receptors (FGFR1FGFR4). However, structural and functional studies of ligandreceptor interactions suggest that other FGF family members are more selective in their receptor activation (Miki et al., 1992; 
Hecht et al., 1995; Ornitz et al., 1996). Whether the observed pleiotrophic effects of FGF-2 on OL lineage cells provides a true reflection of the complexity of FGF signaling remains unclear. It is likely that FGF family members other than FGF-2 play equally significant, but potentially more defined, roles in OL development.

We hypothesized that, during OL lineage progression, cells serially encounter particular FGFs, leading to the selective activation of specific developmentally expressed FGFRs, inducing distinct cellular responses at different stages of maturation. To test this, we examined the effects of FGF-8, FGF-17, FGF-18, and FGF-9 on progenitors and differentiated OLs with respect to proliferation and block of differentiation of OL progenitors, and process elongation, reentry into cell cycle, and downregulation of myelin proteins of differentiated OLs. We show that, in contrast to the broad spectrum of stimulation by FGF-2, other FGF family members induce only discrete subsets of these responses. By using FGFR-specific blocking antibodies, we attribute each response to the activation of a specific FGFR.

\section{Materials and Methods}

Materials. FGF-8 was kindly provided by Dr. C. A. MacArthur (Washington University School of Medicine, St. Louis, MO). FGF-2, FGF-9, FGF-17, and FGF-18 were obtained from PeproTech (Rocky Hill, NJ). Heparin (10,000 U; catalog \#H-3149) was purchased from Sigma (St. Louis, MO). PD173074 (1-tert-butyl-3-[6-(3,5-dimethoxy-phenyl)2-(4-diethylamino-butylamino)-pyrido [2,3-d]pyrimidin-7-yl]-urea) (PD) was a gift from Pfizer Global Research and Development (Ann Arbor, MI). Blocking antibodies to FGFR1 $(\alpha \mathrm{R} 1)$ were provided by ImClone Systems (New York, NY) and to FGFR2 $(\alpha \mathrm{R} 2)$ and FGFR3 $(\alpha \mathrm{R} 3)$ by ProChon Biotech (Rehovot, Israel). Antibodies for immunoblots, anti-FGFR1 and FGFR2, were obtained from Santa Cruz Biotechnology (Santa Cruz, CA) and anti-FGFR3 from Dr. D. Ornitz (Washington University, St. Louis, MO). Transfected cell lines (3T3 cells overexpressing FGFR1 or FGFR2, PC12 overexpressing FGFR3) were provided by Dr. M. J. Hayman (Stony Brook University, Stony Brook, NY).

Cell culture. Purified populations of OL progenitors and mature OLs were prepared, and their purity and phenotype were characterized by immunolabeling with a panel of antibodies as described previously (Bansal et al., 1996; Bansal and Pfeiffer, 1997). Briefly, early progenitors were obtained from mixed primary cultures from neonatal rat telencephalon (postnatal days 1-2) by overnight shaking, followed by differential adhesion and complement lysis with anti-galactocerebroside (GalC). This process resulted in the enrichment of early progenitors by removing terminally differentiated OLs, astrocytes, and macrophages. Cells were plated in 5\% FCS/DMEM in tissue culture plates coated with poly-D,Lornithine ( $50 \mu \mathrm{g} / \mathrm{ml}$; Sigma). After cell attachment for $2-3 \mathrm{~h}$, the medium was changed to serum-free, defined medium mN2 [DMEM with D-glucose $(4.5 \mathrm{mg} / \mathrm{l})$, human transferrin $(50 \mu \mathrm{g} / \mathrm{ml})$, bovine pancreatic insulin $(5 \mu \mathrm{g} / \mathrm{ml}), 3,3,5$-triiodo-L-thyronine (15 nM), sodium selenium (30 nM), D-biotin (10 nM), hydrocortisone (10 nM), sodium pyruvate $(0.11 \mathrm{mg} / \mathrm{ml})$, and penicillin-streptomycin $(10 \mathrm{IU} / \mathrm{ml}$ and $100 \mu \mathrm{g} / \mathrm{ml}$, respectively)] and $0.1 \%$ BSA (all from Sigma). Experimental reagents were added to cultures at this point as described for each experiment.

To obtain differentiated mature OLs, isolated early OL progenitors were allowed to differentiate into OLs by growing them in serum-free $\mathrm{mN} 2$ media for $4 \mathrm{~d}$, followed by $2 \mathrm{~d}$ in cytosine arabinoside $(2 \mu \mathrm{M})$ to eliminate the few remaining undifferentiated proliferating early and late progenitors. After removal of the drug, mature OLs were allowed to grow for an additional $2 \mathrm{~d}$ in the absence or presence of experimental reagents as indicated for each experiment. For immunoblot analysis of proteins, OL cultures were grown in $100 \mathrm{~mm}$ dishes at high density. Process growth analysis was performed using low-density OL cultures, because high density does not allow full process extension by OLs. In general, the effects of different FGFs were tested at various doses. The data are shown mostly for $10-20 \mathrm{ng} / \mathrm{ml}$ doses, except in supplemental Figure 1 (available at www.jneurosci.org as supplemental material).
Immunofluorescence microscopy. Live cells were immunolabeled as described previously (Bansal et al., 1996). Briefly, cells were blocked for nonspecific absorption with HEPES-buffered Earl's balanced salt solution (EBSS-HEPES) containing 3\% normal goat serum (also used for diluting antibodies), double immunolabeled with OL lineage stagespecific markers [early progenitors, A2B5; late progenitors, O4; mature OLs, anti-GalC/sulfatide (R-mAb) or anti-myelin basic protein (MBP) (Sternberger Monoclonals, Lutherville, MD)]. MBP staining was performed after permeabilization (0.05\% saponin) and blocking with 3\% BSA/ PBS. Cells were then labeled with the appropriate secondary antibodies [FITC-conjugated goat anti-mouse IgM ( $\mu$-chain specific for O4 and A2B5; The Jackson Laboratory, Bar Harbor, ME); cyanine 3 (Cy3)-conjugated antimouse IgG ( $\gamma$-chain specific for R-mAb or MBP) and a nuclear label, Hoechst dye (Sigma)]. Washing between steps consisted of three to five 5 min exchanges of $1 \%$ normal goat serum/EBSS-HEPES solution. Cells were then mounted and examined by epifluorescence microscopy.

Bromodeoxyuridine labeling. To identify cells that were in the S-phase of the cell cycle, cells were exposed to bromodeoxyuridine (BrdU) at a final concentration of $50 \mu \mathrm{M}$ for $3-4 \mathrm{~h}$ at $37^{\circ} \mathrm{C}$ for incorporation into newly synthesized DNA. Cells were then fixed with ethanol/glacial acetic acid (95:5) at $-20^{\circ} \mathrm{C}(2 \mathrm{~min})$, denatured with $2 \mathrm{~N} \mathrm{HCl}(10 \mathrm{~min})$, neutralized with $0.1 \mathrm{M}$ sodium borate, $\mathrm{pH} 8.5$ (10 min), incubated with antiBrdU (1:50, 20 min; Becton Dickinson, Lincoln Park, NJ) followed by goat anti-mouse IgG conjugated to Cy3 (The Jackson Laboratory), and mounted for immunofluorescent examination and analysis.

Immunoblotting and immunoprecipitation. Cells were harvested in lysis buffer ( $10 \mathrm{~mm}$ Tris-HCl, $150 \mathrm{~mm} \mathrm{NaCl}, 0.1 \%$ SDS, $1 \%$ deoxycholate, and $1 \% \mathrm{NP}-40, \mathrm{pH} 7.4)$ with protease and phosphatase inhibitors $(2 \mathrm{~mm}$ PMSF, $2 \mu \mathrm{g} / \mathrm{ml}$ leupeptin, $2 \mu \mathrm{g} / \mathrm{ml}$ aprotinin, and $1 \mathrm{~mm}$ vanadate) on ice and cup sonicated $\left(30 \mathrm{~s}, 4^{\circ} \mathrm{C}\right)$. The homogenates were then incubated $(30$ $\mathrm{min}$, on ice) and centrifuged $\left(15,000 \times \mathrm{g}, 10 \mathrm{~min}, 4^{\circ} \mathrm{C}\right)$. The protein concentration was assayed with the DC Protein Assay kit (Bio-Rad, Hercules, CA). Aliquots of equal amounts of total protein from different experimental conditions were electrophoresed on $12 \%$ SDS polyacrylamide gels and transferred onto polyvinylidene difluoride membranes. The membranes were blocked for $1 \mathrm{~h}$ (Tris-buffered saline, $5 \%$ nonfat powdered milk, $0.2 \%$ Tween 20 , or $10 \%$ BSA) and incubated for $1 \mathrm{~h}$ in primary antibodies: MBP (Sternberger Monoclonals); myelin oligodendrocyte glycoprotein (MOG) (Dr. C. Linington, Aberdeen, UK); FGFR1, FGFR2, cyclin-dependent kinase 2 (Cdk2), and cyclin E (Santa Cruz Biotechnology); FGFR3 (Dr. D. Ornitz, St. Louis, MO); phosphomitogen-activated protein kinase (MAPK) (Promega, Madison, WI); and $\beta$-actin (Sigma); phospho-tyrosine (4G10; Upstate Biotechnology, Waltham, MA). The membranes were then incubated for $30 \mathrm{~min}$ in appropriate secondary antibodies conjugated to horseradish peroxidase (1:10,000; Santa Cruz Biotechnology). The membranes were developed using the ECL Plus kit (Amersham Biosciences, Arlington Heights, IL).

For immunoprecipitation, protein lysates $(400 \mu \mathrm{g})$ extracted with lysis buffer were precleared with $20 \mu \mathrm{l}$ of protein A-Sepharose beads (Amersham Biosciences, Piscataway, NJ) for $30 \mathrm{~min}$ and incubated overnight with anti-FGFR2 $(1: 1000)$ at $4^{\circ} \mathrm{C}$. Protein A-Sepharose beads $(0.01 \mathrm{mg} /$ $\mathrm{ml}$ ) were added for $2 \mathrm{~h}$ at $4^{\circ} \mathrm{C}$, and immunocomplexes were separated by centrifugation, washed four times with lysis buffer, and analyzed by immunoblotting as described above.

Statistical analysis. Data are presented as mean \pm SEM unless stated otherwise. All statistical analyses were performed using Student's paired $t$ tests with a critical probability of $p<0.05$. SEMs were calculated for all data using $n$ values of multiple independent experiments (stated in figure legends), each performed in triplicate wells. Cell counts were typically performed from at least 15-20 fields of view per well using $40 \times$ magnification. For proliferation and differentiation studies, $\sim 800-1400$ cells were counted per well. For process outgrowth studies, $120-150$ cells were examined per well. Statistical significance is shown (labeled by asterisk) only when differences were not clearly obvious.

\section{Results}

Previous studies have demonstrated that FGF-2 induces multiple, stage-specific responses by cells of the OL lineage (Bansal, 2002). To determine whether these cellular responses are a gen- 
eral property of all FGFs, we treated OL lineage cells in culture to either FGF-8 (and its structurally related subfamily members FGF-17 and FGF-18) or FGF-9. The effects of these FGFs on OL progenitors and terminally differentiated OLs were analyzed with a special focus on FGF-8 and FGF-9. Immunolabeling of cells with developmental stage-specific antibodies, in conjunction with cell morphology, were used to identify cells within specific stages of development as described previously (Pfeiffer et al., 1993; Bansal et al., 1996). In brief, in conjunction with characteristic morphology, O4 was used to label both late progenitors (Pro-OLs; will be referred to as "OL progenitors") and differentiated OLs, whereas anti-GalC and anti-MBP were used to identify differentiated OLs (GalC expression precedes MBP).

\section{OL progenitors respond differentially to} select FGF family members

Proliferation

To determine the effect of individual FGFs on the proliferation of OL progenitors, we treated cultures with the different FGFs (10 $\mathrm{ng} / \mathrm{ml})$ for $0-48 \mathrm{~h}$, concluding with a $4 \mathrm{~h}$ incubation with BrdU to provide a measure of cell cycle progression (Fig. $1 A, B)$. Whereas $\sim 5 \%$ of untreated OL progenitors incorporated BrdU, FGF-2 induced a robust sixfold increase in the percentage of $\mathrm{BrDU}^{+}$cells. In contrast, FGF-8, FGF-9, and FGF-17 failed to stimulate BrdU incorporation, and FGF-18 was only moderately stimulatory. This was true even at doses up to $40-80 \mathrm{ng} / \mathrm{ml}$ (supplemental Fig. 1A, available at www. jneurosci.org as supplemental material) or when the durations of BrdU incorporation were increased to $24 \mathrm{~h}$ (supplemental Fig. $1 E$, available at www.jneurosci.org as supplemental material); thus, the inability of these FGFs to stimulate the proliferation of OL progenitors was not attributable to limiting doses of growth factors or slower cell cycling times. We conclude that not all FGFs stimulate the proliferation of OL progenitors.

Activation of MAPKs [ERKs (extracellular signal-regulated kinases)] is a downstream consequence of FGF-2 signaling in OL progenitors (Baron et al., 2000; Bansal, 2002). Therefore, we investigated whether the differences in the mitogenic potential between FGF-2 and FGF-8 were attributable to differences in MAPK activation. Immunoblot analyses on equal amounts of total proteins, using anti-phospho-MAPK was performed as a function of time (Fig. 1C). MAPK activation by FGF-2 was rapid, robust, and sustained, whereas activation by FGF- 8 was delayed, weak, and transient. We conclude that differences in the mitogenicity of FGFs may be attributable in part to differential activation of MAPK.

We next asked whether the inability of FGF- 8 or FGF-9 to induce changes in OL progenitor proliferation or differentiation
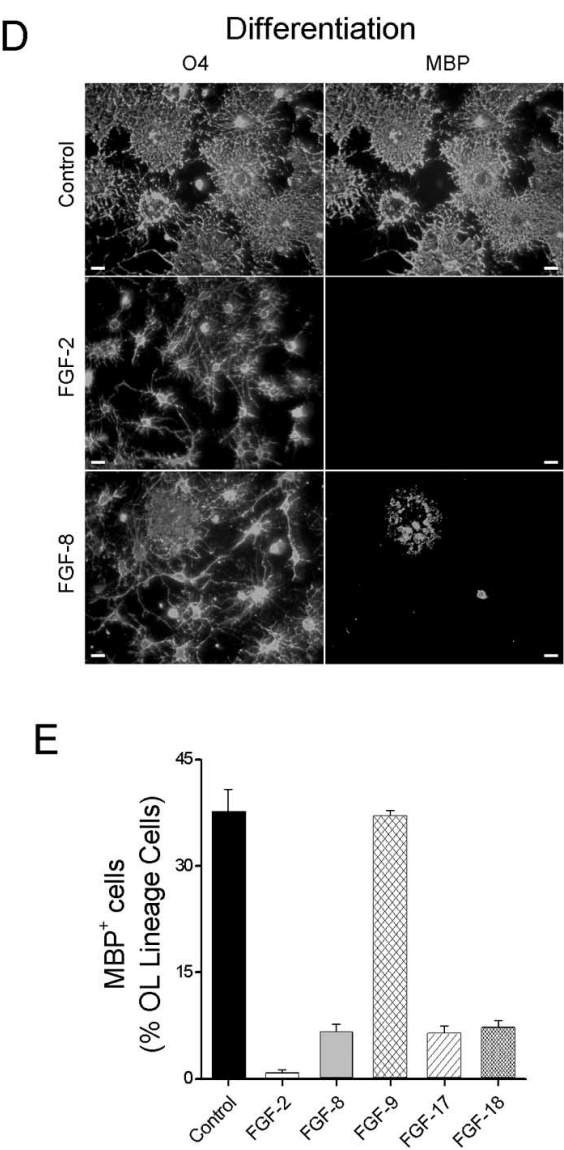

Figure 1. Diverse effects of different FGFs on proliferation and differentiation of oligodendrocyte progenitors. OL progenitors

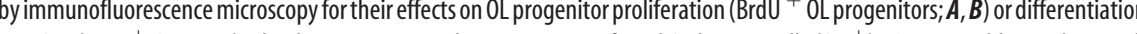
的

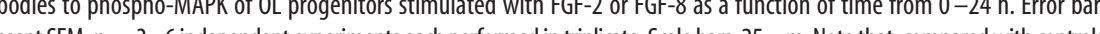
represent SEM; $n=3-6$ independent experiments each performed in triplicate. Scale bars, $25 \mu \mathrm{m}$. Note that, compared with controls, FGF-2 stimulates proliferation and inhibits differentiation of OL progenitors, FGF-8, FGF-17, and FGF-18 inhibit differentiation without significantly affecting proliferation, and FGF-9 has no affect on either proliferation or differentiation of $0 \mathrm{~L}$ progenitors.

was attributable to a lack of appropriate heparan sulfate proteoglycans expressed by these cells. These cell surface molecules act as coreceptors to FGFRs and are critical for proper FGF receptormediated signaling (Yayon et al., 1991; Bansal and Pfeiffer, 1994; Turnbull et al., 2001; Winkler et al., 2002). However, the addition of $2 \mu \mathrm{g} / \mathrm{ml}$ heparin, which satisfies the coreceptor requirement for all FGFs, did not alter these results (supplemental Fig. 1C, available at www.jneurosci.org as supplemental material). We conclude that the lack of responses mediated by FGF-8 or FGF-9 on proliferation was not attributable to limiting levels of heparan sulfate proteoglycans.

\section{Differentiation}

In addition to enhancing the proliferation of OL progenitors, FGF-2 also suppresses their entry into terminal differentiation at the late progenitor stage. We therefore examined the ability of other FGFs to inhibit the differentiation of OL progenitors (Fig. $1 D, E)$. Cultures were treated with FGF-2, FGF-8, FGF-9, FGF17 , or FGF-18 from 0 to $4 \mathrm{~d}$ in culture and then analyzed by 
A

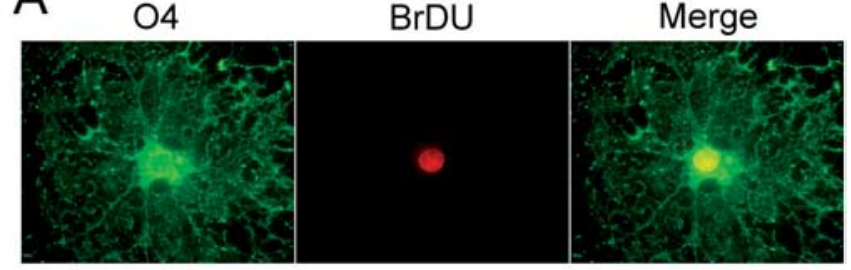

B

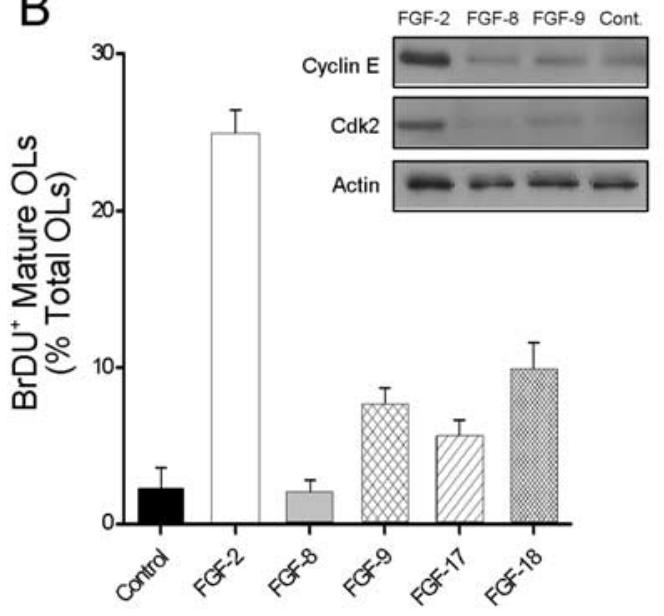

Figure 2. The effect of FGF family members on cell cycle reentry in mature oligodendrocytes. Mature $0 \mathrm{Ls}$ were grown in the absence (control) or presence of FGF-2, FGF-8, FGF-9, FGF-17, or FGF-18 for $2 \mathrm{~d}$ (plus BrdU for the last $3 \mathrm{~h}$ ). The number of OLs incorporating BrdU and the level of expression of Cdk2 and cyclin E were determined to identify cell cycle reentry. $\boldsymbol{A}$, Example of a mature $0 \mathrm{~L}$ double labeled with 04 and anti-BrdU after FGF-2 treatment. $B$, Quantification of the percentage of mature $0 \mathrm{Ls}$ incorporating BrdU (expressed as a percentage of total $0 \mathrm{Ls}$ ) after treatment with different FGF family members. Inset, Immunoblot analysis for the expression of the cell cycle proteins cyclin E and Cdk2 after exposure to FGF-2, FGF-8, or FGF-9 compared with untreated controls. The blots were reprobed for actin to demonstrate equal protein loading. Error bars represent SEM; $n=3-5$ independent experiments, each performed in triplicate.

double immunolabeling cells with $\mathrm{O} 4$ and MBP. As expected, compared with untreated controls, FGF-2 inhibited the differentiation of OL progenitors, as shown by the maintenance of a progenitor-like simple morphology (Fig. 1D) and a reduced number of $\mathrm{MBP}^{+}$OLs (Fig. 1 E). FGF-8, FGF-17, or FGF-18 were also very effective at blocking the appearance of $\mathrm{MBP}^{+}$cells. In contrast, FGF-9 did not block the progression of OL progenitors into mature OLs (Fig. $1 E$ ), even at doses up to $40-80 \mathrm{ng} / \mathrm{ml}$ or in the presence of heparin (supplemental Fig. $1 B, D$, available at www.jneurosci.org as supplemental material), and the cells displayed a morphology similar to the controls in Figure $1 D$ (data not shown).

In summary, we found that FGF-2, and to a far lesser extent FGF-18 (but not FGF-8, FGF-17, or FGF-9), stimulated the proliferation of OL progenitors and that FGF-2, FGF-8, FGF-17, and FGF-18 (but not FGF-9) inhibit the differentiation of OL progenitors into mature OLs. Although FGF-8 and FGF-17 did not lead to increased proliferation, they nevertheless were effective in blocking differentiation, suggesting that certain FGFs are capable of uncoupling the proliferation/differentiation interface. Finally, OL progenitors failed to respond to FGF-9, demonstrating that OL progenitors are not responsive to all FGFs.

\section{A}
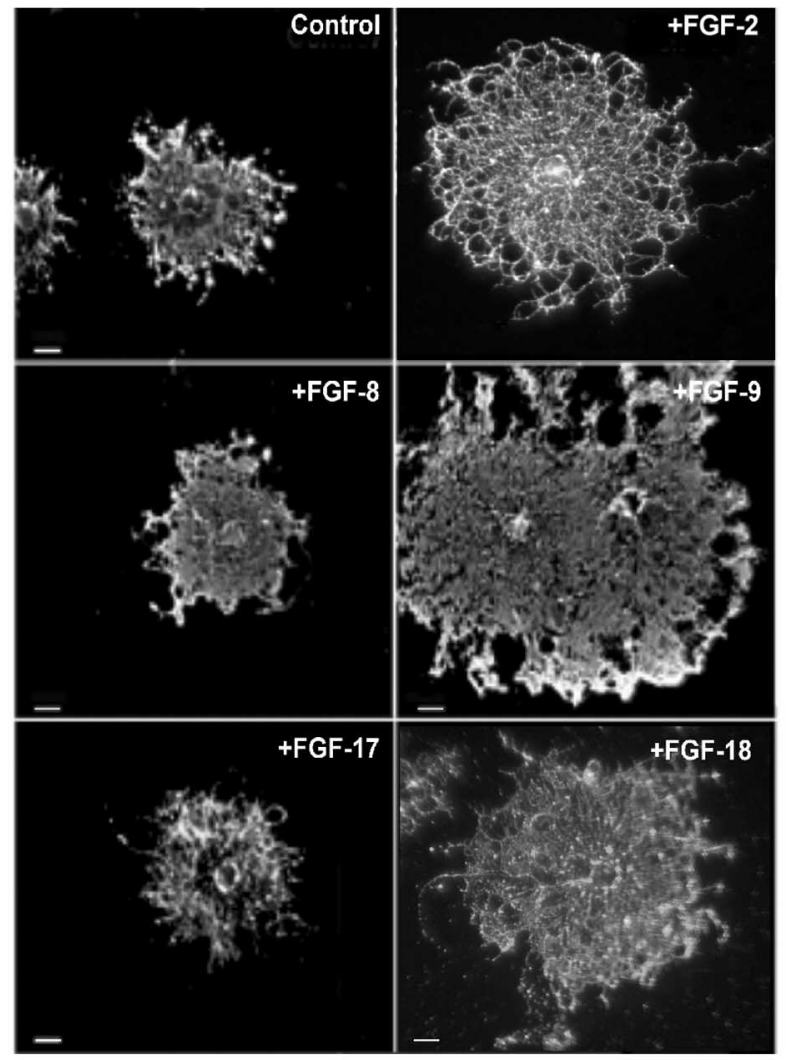

\section{$B$}

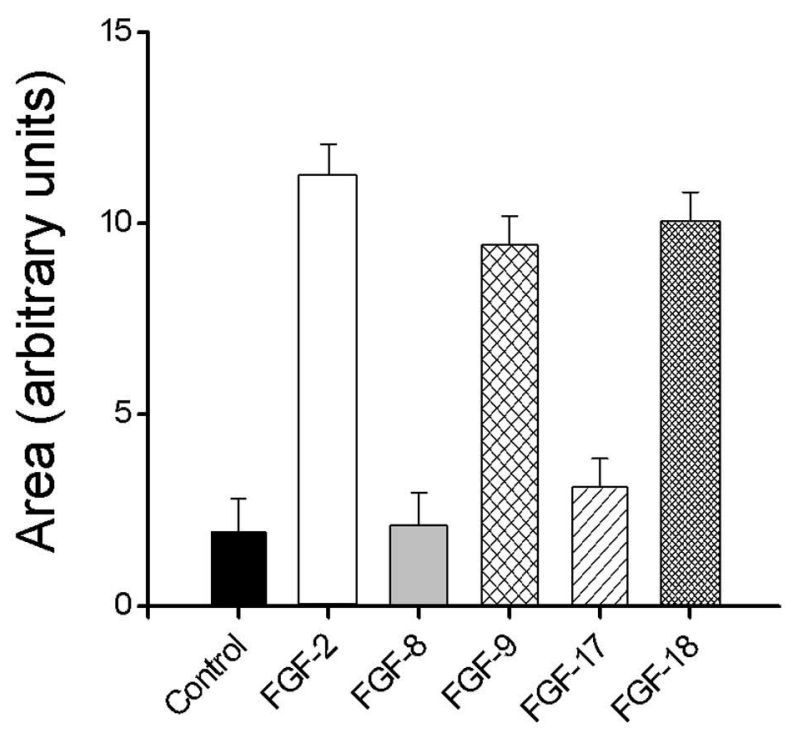

Figure 3. Selective induction of process elongation in mature oligodendrocytes by specific FGFs. $\boldsymbol{A}$, Mature OLs were grown in the absence (control) or presence of FGF-2, FGF-8, FGF-9, FGF-17, or FGF-18 for $2 \mathrm{~d}$, after which they were double immunolabeled with the $0 \mathrm{~L}$ markers 04 and MBP (04 is shown). B, Quantification of $0 \mathrm{~L}$ areas illustrating that FGF-2, FGF-9, and FGF-18, but not FGF-8 or FGF-17, induced process elongation as shown by increases in cell areas. Scale bars, $25 \mu \mathrm{m}$. Error bars represent SEM; $n=3-9$ independent experiments, each performed in triplicate. 
Mature OLs respond differentially to select FGF family members

Exposing mature OLs in culture to FGF-2 results in multiple responses, including cell cycle reentry, process elongation, and the selective downregulation of myelin proteins and FGFR2 (Bansal, 2002). To determine whether other FGFs demonstrate greater signaling specificity than FGF-2, we first allowed OL progenitors to differentiate into mature OLs that expressed myelin proteins and elaborated myelin-like membranes and then exposed them to FGF-2, FGF-8, FGF-9, FGF-17, or FGF-18 $(10 \mathrm{ng} / \mathrm{ml})$ for $2 \mathrm{~d}$ and assayed for each of the these responses.

\section{Reentry of differentiated OLs into the cell cycle}

FGF-mediated reentry of differentiated OLs into the cell cycle was analyzed by double immunolabeling mature OLs with $\mathrm{O} 4$ or MBP and anti-BrdU ( $3 \mathrm{~h}$ previous exposure of cells to BrdU) (Fig. 2A, O4labeled OL is shown). The numbers of $\mathrm{BrdU}^{+}$OLs are expressed as a percentage of total number of mature OLs. Whereas differentiated OLs rarely incorporated BrdU $(<3 \%)$, application of FGF-2 increased the total number of OLs incorporating BrdU by more than sixfold (Fig. $2 B$ ). In contrast, FGF-8, FGF-9, FGF-17, or FGF-18 exerted only minor, statistically insignificant effects compared with FGF-2. The FGF-2 mediated reentry into S-phase of the cell cycle was also accompanied by an increase in the expression of cyclin E and cyclin dependent kinase 2 (Cdk2), whereas no such changes were observed with FGF-8 or FGF-9 (Fig. $2 B$, inset). We conclude that, unlike FGF-2, FGF-8, FGF-9, FGF-17, and FGF-18 are poor stimulators of cell cycle reentry by differentiated OLs.

\section{Stimulation of process elongation of differentiated OLs}

Mature OLs that had made myelin-like membranes were exposed to FGF-2, FGF-8, FGF-9, FGF-17, or FGF-18 in low-density cultures to allow space for further process elongation and double immunolabeled with O4 and anti-MBP. As expected, FGF-2 increased the size (area) of OLs compared with untreated controls (Fig. 3A,B). Treatment of OLs with either FGF-9 or FGF-18, but not FGF-8 or FGF-17, produced similar increases in cell size (Fig. $3 A, B)$. Whereas FGF-2-mediated increase in OL processes length was accompanied by a loss of myelin-like membranes, no such loss in membrane sheets was observed in the case of FGF-9 and FGF-18. The inability of FGF-8 and FGF-17 to increase cell size suggests that OL lineage cells have the capacity to discriminate between different FGF family members.

\section{Downregulation of myelin proteins}

Downregulation of myelin proteins was measured in OLs exposed to FGF-2, FGF-8, FGF-9, FGF-17, or FGF-18 in cultures grown at high density to provide sufficient material for immunoblot analyses. Consistent with our previous observation (Bansal and Pfeiffer, 1997), FGF-2 induced a downregulation of several myelin proteins including proteolipid protein, $2^{\prime}, 3^{\prime}$-cyclic nucle-

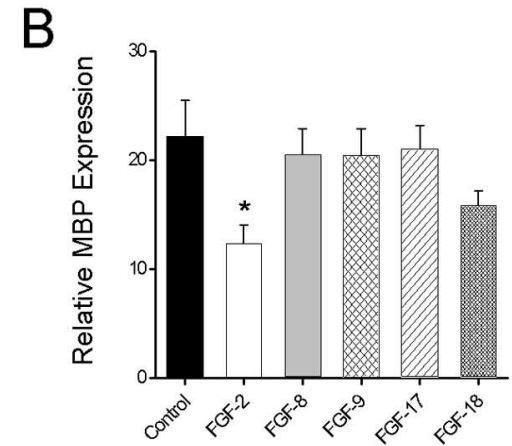

C

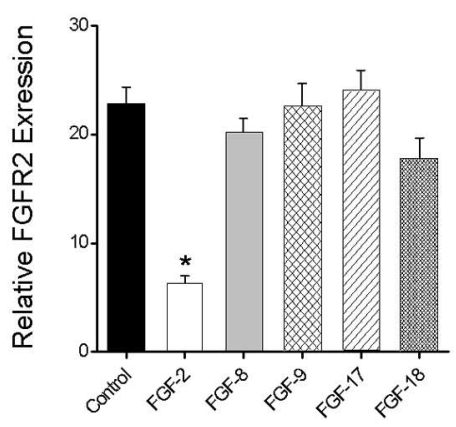

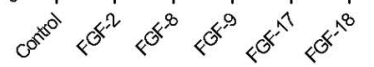
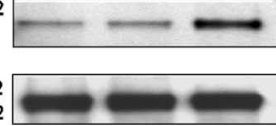

Figure 4. Downregulation of myelin proteins is specific to FGF-2. A, Mature OLs were grown in the absence (control) or presence of FGF-2, FGF-8, FGF-9, FGF-17, or FGF-18 for $2 d$, and the expressions of MBP, MOG, and FGFR2 were determined by nalyses. Equal amounts of protein were loaded in each lane as confirmed by reprobing blots with antibodies to actin.

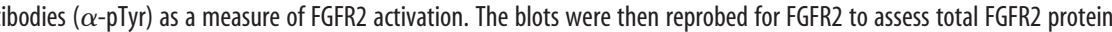
showing that FGFR2 is activated by FGF-2, but not FGF-8, before being subsequently downregulated. Error bars represent SEM; $n=3$ independent experiments performed in triplicate. ${ }^{*} p<0.01 .{ }^{* *}$ in $A$, Nonspecific band.

otide 3'-phosphodiesterase, neurofascin 155, MBP, and MOG (as an example only MBP and MOG are shown), and FGFR2 [FGF-2 reduced MBP and FGFR2 expression to $55 \pm 8$ and $28 \pm 3 \%$ of control, respectively (Fig. $4 A-C$ )]. In contrast, FGF-8, FGF-9, FGF-17, or FGF-18 did not induce significant downregulation. To determine whether FGFR2 was activated before its downregulation, we exposed mature OLs to either FGF-2 or FGF-8 for 15 min and then immunoprecipitated FGFR2 from cell lysates with antibodies to FGFR2 (Fig. 4D). Immunoblots of the precipitates using antibodies to phospho-tyrosine indicated that FGFR2 was phosphorylated (activated) in response to FGF-2 but not FGF-8.

In summary, although FGF-2 induced in mature OLs each of the studied responses, FGF-9 and FGF-18 stimulated only process elongation, and FGF-8 and FGF-17 failed to elicit any effect.

\section{There is a developmental switch in the expression of FGF receptors}

We next asked whether the specificity we observed with certain FGFs at different stages of OL maturation correlated with changes in the developmental expression patterns of FGFRs. We first confirmed that the polyclonal rabbit FGFR antibodies can distinguish between FGFR1, FGFR2, and FGFR3 using cell lines that overexpressed individual FGFRs (Fig. 5A).

We then examined the FGFR expression of cells in three different stages of development (EP, early progenitors; Pro-OL, late progenitors; OL, differentiated OLs) and purified myelin (My) by immunoblotting. Cells at these stages were obtained and characterized as described previously (Bansal et al., 1996). Consistent with mRNA expression patterns that we showed previously (Ban- 
A

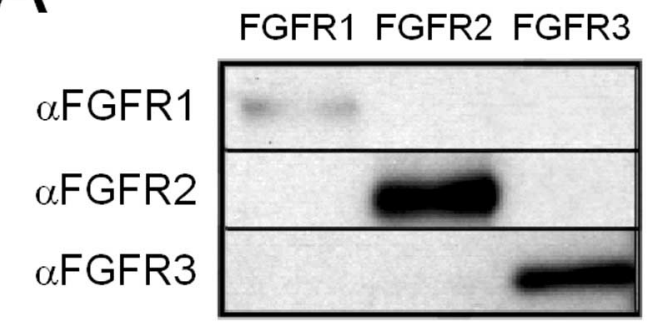

B

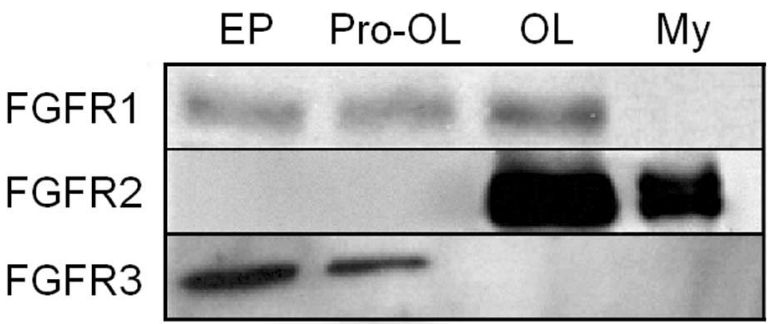

Figure 5. Developmental expression patterns of FGFR1, FGFR2, and FGFR3 protein. $\boldsymbol{A}$, Protein lysates from transfected cell lines overexpressing FGFR1, FGFR2, or FGFR3 were loaded in adjacent lanes and analyzed by immunoblotting to test the specificity of anti-receptor antibodies for each FGFR. $\boldsymbol{B}$, Equal amounts of total proteins analyzed by immunoblotting shows the developmental protein expression patterns of FGFR1, FGFR2, and FGFR3 in early progenitors $(E P)$, late progenitors (Pro-OLs), terminally differentiated oligodendrocytes (OLs), and myelin (My). A representative experiment of three to five independent experiments is shown. Note that there is a developmental switch from FGFR3 to FGFR2 as late progenitors differentiate into mature $0 \mathrm{Ls}$.

sal et al., 1996), FGFR1 protein was expressed throughout OL development, FGFR2 was upregulated as OL entered terminal differentiation, and FGFR3 was expressed by progenitors and downregulated during terminal differentiation (Fig. 5B). In addition, FGFR2, but not FGFR1 or FGFR3 was present in myelin. These data show that there is a changing pattern of FGFR expression during OL lineage progression.

\section{The diversity of responses induced by different FGFs is} attributable to their selective interaction with specific FGFRs The changing patterns of FGFRs during OL development suggests that the observed stage-specific responses induced by different FGFs may be attributable to specific FGF/FGFR interactions. To test this hypothesis, we used newly developed FGFR blocking antibodies that are specific to FGFR1, FGFR2, or FGFR3 (supplemental Fig. 2 and Methods, available at www.jneurosci.org as supplemental material) (Rauchenberger et al., 2003) and examined the effects of blocking signaling via these receptors on responses of progenitor and differentiated OLs induced by different FGFs. Blocking antibodies were used at various doses: antiFGFR1 $(28,55,85$, and $170 \mu \mathrm{g} / \mathrm{ml})$, anti-FGFR2 (20, 40, and 80 $\mu \mathrm{g} / \mathrm{ml})$, and anti-FGFR3 $(6,12,24$, and $32 \mu \mathrm{g} / \mathrm{ml})$. In addition, the general FGFR inhibitor (PD173074, $100 \mathrm{nM}$ ), which inhibits signaling via all FGFRs in OL-lineage cells (Bansal et al., 2003a), was used as a control.

\section{Progenitors}

We first asked whether the proliferative response of OL progenitors to FGF-2 was mediated via FGFR1 or FGFR3, both of which are expressed during this stage of development (Fig. 6A). OL progenitors were grown in the presence of FGF-2 for $3 \mathrm{~d}$, with or without $\alpha \mathrm{R} 1$ or $\alpha \mathrm{R} 3$, and analyzed for BrdU incorporation.
Whereas either $\alpha$ R1 (or PD173074) almost completely abolished the proliferative response of OL progenitors to FGF-2 at all doses tested, $\alpha \mathrm{R} 3$ showed no effect even at the highest dose used (32 $\mu \mathrm{g} / \mathrm{ml}$ ) (Fig. $6 \mathrm{~A}$ ). As a control, addition of antibody alone (without FGF-2) had no effect (data not shown). We conclude that FGFR3 signaling is not necessary for OL proliferation. This is consistent with the observation that FGF-8, a proposed ligand of FGFR3 but not of FGFR1 (Xu et al., 2000), did not stimulate proliferation of OL progenitors (Fig. $1 A, B$ ). However, FGF-8 did inhibit OL progenitors from entering terminal differentiation $\left(\mathrm{GalC}^{+}\right.$cells) (Figs. $\left.1 \mathrm{D}, \mathrm{E}, 6 \mathrm{~B}\right)$. This inhibition was prevented by either PD173074 or $\alpha \mathrm{R} 3(6 \mu \mathrm{g} / \mathrm{ml}$ ) but not by $\alpha \mathrm{R} 1$ (even at 85 $\mu \mathrm{g} / \mathrm{ml}$ ). Similar to FGF-8, the subfamily members FGF-17 and FGF-18 also induced a block of differentiation via FGFR3 (Fig. $6 \mathrm{~B}$ ). As expected, when FGF-2 (which targets all FGFRs) was used as the ligand, both $\alpha \mathrm{R} 1$ and $\alpha \mathrm{R} 3$ were needed to release the block of differentiation (Fig. $6 \mathrm{~B}$ ). We conclude that proliferation of $\mathrm{OL}$ progenitors by FGF-2 requires FGFR1. In contrast, inhibition of OL progenitor differentiation by FGF-8, FGF-17, and FGF-18 requires FGFR3.

\section{Differentiated OLs}

We next addressed the question of whether FGF-2-induced reentry of differentiated OLs into the cell cycle was mediated by FGFR1 or FGFR2, both of which are expressed by mature OLs (Fig. 7A). Mature OLs were exposed to FGF-2 in the absence or presence of either $\alpha \mathrm{R} 1$ or $\alpha \mathrm{R} 2$ for $2 \mathrm{~d}$ and analyzed for BrdU incorporation. Whereas either $\alpha \mathrm{R} 1$ or PD173074 significantly attenuated FGF-2-mediated cell cycle reentry, $\alpha \mathrm{R} 2$ exerted no effect, indicating that FGF-2-induced cell cycle reentry by mature OLs requires the activation of FGFR1.

We next examined whether the stimulation of OL process elongation by FGF-2, FGF-9, or FGF-18 was mediated via activation of FGFR1 or FGFR2 (Fig. 7B). Mature OLs were exposed to FGF-2, FGF-9, or FGF-18 for $2 \mathrm{~d}$ in the absence or presence of $\alpha \mathrm{R} 1$ or $\alpha \mathrm{R} 2$, and the size of OLs (area) was analyzed as an indicator of process elongation. The FGF-2-, FGF-9-, and FGF-18induced increases in cell size were completely abolished by either $\alpha \mathrm{R} 2$ or PD173074; in contrast, $\alpha \mathrm{R} 1$ failed to inhibit this effect even at higher doses. Thus, FGF-2, FGF-9, and FGF-18 stimulate OL process elongation via FGFR2.

Finally, we asked whether downregulation of myelin-specific proteins and FGFR2 induced by FGF-2 was mediated by the action of a specific FGFR (Fig. $7 C$ ). In these experiments, mature OLs were exposed to FGF-2 for $2 \mathrm{~d}$ in the absence or presence of $\alpha \mathrm{R} 1, \alpha \mathrm{R} 2, \alpha \mathrm{R} 3$, or PD173074 and analyzed for FGFR2 and MOG expression by immunoblotting. As expected, FGF-2 by itself downregulated the expression of FGFR2 and MOG protein to $21.9 \pm 8.4$ and $23.2 \pm 9.3 \%$, respectively, of control levels. This effect was significantly reversed by either $\alpha \mathrm{R} 1$ or PD173074 but not by $\alpha \mathrm{R} 2$ or $\alpha \mathrm{R} 3$ (Fig. 7Ca, $\mathrm{Cb}$ ). Although FGFR3 protein is not expressed by mature OLs, $\alpha \mathrm{R} 3$ was used as an additional control. These results show that the downregulation by FGF-2 of FGFR2 and myelin proteins such as MOG is mediated via FGFR1.

In summary (Fig. 8), different FGFs target specific maturation stages within the same developmental lineage. Only subsets of the overall FGF-2-mediated responses were induced by other FGFs. Specifically, FGF-2 appears to target both OL progenitors and mature OLs, activating all expressed FGFRs, leading to the induction of multiple responses. Conversely, FGF-8 (and FGF-17) targeted only OL progenitors, specifically inhibiting their terminal differentiation via the activation of FGFR3. FGF-9, which had no observable effect on OL progenitors, specifically targeted differ- 
entiated OLs, resulting in increased process growth via FGFR2 signaling. FGF-18 affected both progenitors and mature OLs via FGFR3 and FGFR2, respectively. Furthermore, FGF-2-mediated activation of FGFR1 results in cell cycle entry in both OL progenitors and differentiated OLs and the downregulation of myelin proteins in mature OLs. We conclude that the differential responses of OLs during development are a consequence of the selective activation of FGFRs that are developmentally regulated.

\section{Discussion}

In this study, we have shown that, during the course of OL development, distinct physiological responses result from signaling via a changing repertoire of specific FGF/FGFR pairs. This is accomplished on the one hand by ligand availability, and on the other hand by developmentally regulated changes in receptor protein expression. We suggest that these interrelated regulatory events provide a mechanism for ordering the sequence of multiple responses produced by FGF signaling that is important for OL lineage progression and myelination. Interruption of this carefully orchestrated pattern is likely to have important consequences for myelin pathology. Cultured OL lineage cells provide an excellent model system for studying such specificity of FGF/FGFR interactions in a developmental context (Bansal et al., 1996).

\section{FGF/FGFR specificity}

FGFs are grouped in several subfamilies based on sequence homology. One subfamily comprises FGF-8, FGF-17, and FGF-18, which have $70-80 \%$ amino acid identity and overlapping expression (Itoh and Ornitz, 2004). In our studies, these FGFs also showed functional similarities: for example, all three had little effect on the proliferation of OL progenitors but blocked their terminal differentiation. Thus, there is a correspondence between the activities elicited by individual FGF family members and their primary structure.

Previous studies indicate that different FGFs have different degrees of selectivity for specific FGFRs (Miki et al., 1992; Ornitz and Leder, 1992; Yayon et al., 1992). For example, in these studies, the FGF-8, FGF-17, FGF-18 subfamily was most selective for FGFR3 (Xu et al., 2000), whereas FGF-9 activated both FGFR3 and FGFR2 (Hecht et al., 1995; Ornitz et al., 1996). Nevertheless, these selectivities were observed in transfected overexpressing cell lines that do not normally express FGFRs, and only the mitogenic response was measured. However, recent in vivo genetic studies suggest that this selectivity may be more complex (Hebert et al., 2003). Here we examined a range of both mitogenic and nonmitogenic responses of FGFs on primary cells of the OL lineage that endogenously express FGFRs, using for the first time, newly developed receptor-specific blocking antibodies. Consistent with transfected cell line studies, we show that, in OL progenitors, FGF-8 and FGF-17 signal through FGFR3; FGF-18, conversely, signals via either FGFR2 or FGFR3, demonstrating less selectivity compared with other members of the subfamily. However, in contrast to cell lines, in OL progenitors, FGF-9 signals only via FGFR2. These data emphasize the complexity of FGF signaling
B

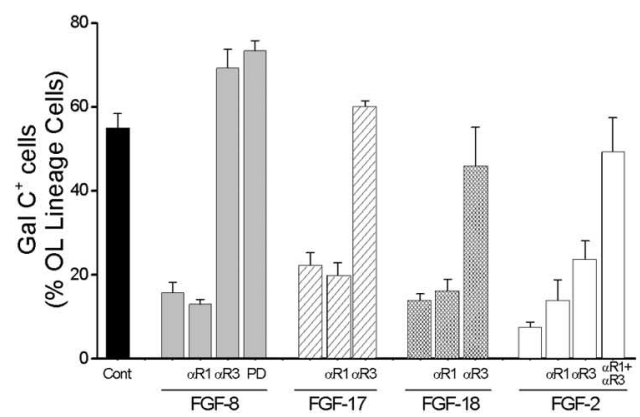

Figure 6. Oligodendrocyte progenitors require FGFR1 for FGF-2-induced proliferation, but FGFR3 for FGF-8, FGF-17, and the increase in BrdU incorporation, $\boldsymbol{B}, 0 \mathrm{~L}$ progenitors were grown in the presence of FGF-2, FGF-8, FGF-17, or FGF-18, with or The arrest of differentiation mediated by FGF- 8 , FGF-17, and FGF-18 was prevented by $\alpha$ R3 but not by $\alpha$ R1. The FGF- 8 -induced of differentiation. Error bars represent SEM; $n=3-12$ independent experiments, each performed in triplicate.

and show that FGF/FGFR interactions may vary among different cell types.

The study of signaling pathways initiated by each FGFR is an emerging field of investigation. Despite structural similarities among FGF family members and receptor signaling domains, specific FGFRs can exhibit different physiological responses, suggesting differences in their signaling patterns. For example, in gene-targeted disruptions of specific FGFRs, signals mediated by one receptor cannot be rescued by those mediated by another (Deng et al., 1994; Arman et al., 1998). One mechanism may involve differences in the tyrosine kinase domains: FGFR3 lacks one of two specific tyrosine residues essential for the mitogenicity of FGFR1; consistent with this, proliferation in both BaF3 cells and OL progenitors (present study) are promoted less effectively by activation of FGFR3 than of FGFR1 (Ornitz et al., 1996; Wang and Goldfarb, 1997). In addition, receptors activating the same pathway may do so with different potency: in PC12 cells, the MAP kinase pathway is activated strongly by FGFR1 but only weakly by FGFR3 (Wang et al., 1994; Shaoul et al., 1995). Consistent with this, here we show that, in OL progenitors, FGF-2/ FGFR1 signaling leads to proliferation and robust MAP kinase activation, whereas FGF-8/FGFR3 does not. Nevertheless, FGFR3 does induce strong signals for gene expression, primarily through Ras-independent signaling pathways in PC12 cells (Choi et al., 2001). The specific signaling pathways emerging from the activation of each FGF ligand/receptor pair in the OL lineage cells remain to be determined. The connection of receptor ligand pairs to specific responses established in this study paves the way to address these issues.

\section{FGF regulation of OL proliferation and differentiation}

The decision to cease proliferation and enter terminal differentiation is a critical event in development. FGF-8 arrested the progression of OL progenitors into terminal differentiation, even in the absence of proliferation. Thus, the regulation of the proliferation and differentiation interface, often thought to involve closely interrelated mechanisms, must in fact be parallel, separate regulatory events that can be physiologically uncoupled. Blocking antibody studies show that FGF-2 induces proliferation of OL progenitors via FGFR1, and that FGF-8 inhibits differentiation of 
A

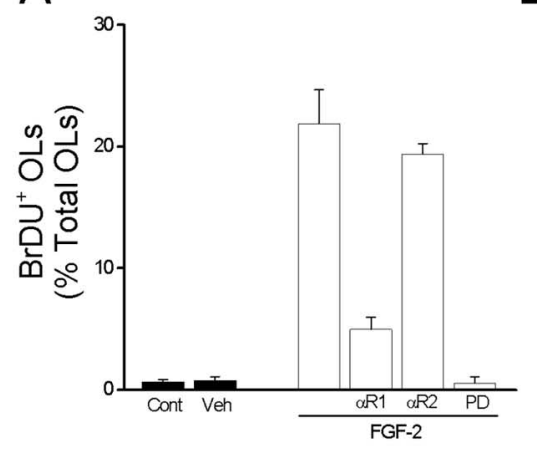

$\mathrm{Ca}$

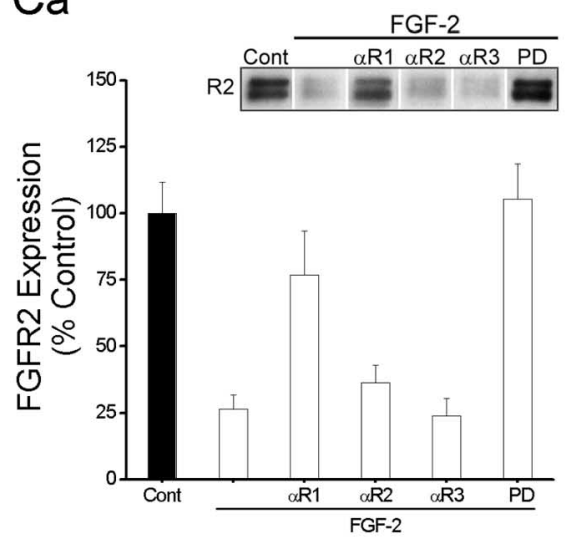

B

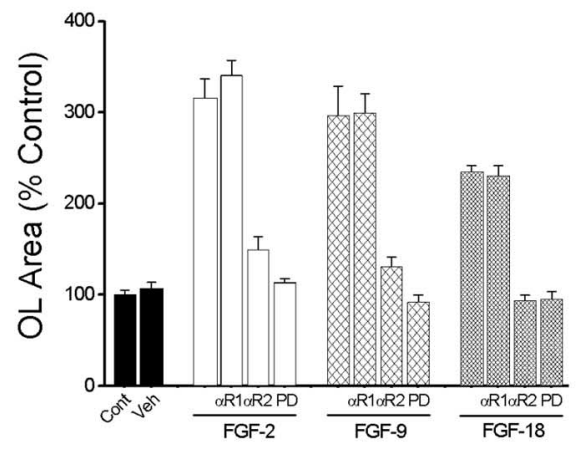

$\mathrm{Cb}$

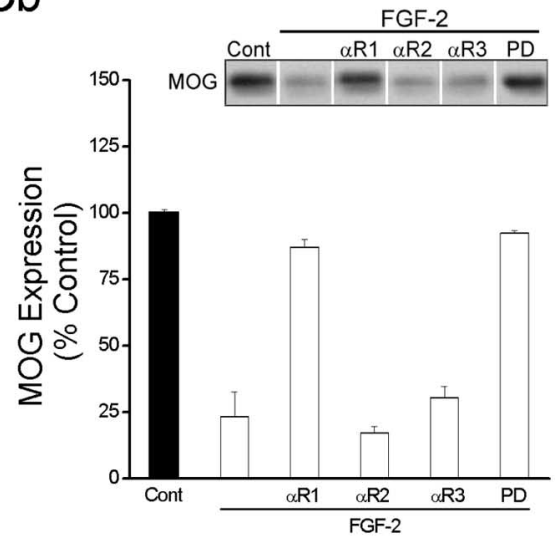

Figure 7. Reentry of mature oligodendrocytes into the cell cycle and downregulation of myelin proteins is mediated by FGFR1; stimulation of process elongation is mediated by FGFR2. Mature 0Ls were exposed for $2 \mathrm{~d}$ to FGF-2, FGF-9, or FGF-18 with or without blocking antibodies to FGFR1 ( $\alpha \mathrm{R} 1)$ or FGFR2 $(\alpha \mathrm{R} 2)$. $\boldsymbol{A}$, The stimulation by FGF-2 of BrdU incorporation in mature 0Ls compared with untreated controls (Cont) was attenuated by $\alpha$ R1 or PD but not by $\alpha$ R2. B, Sizes (areas) of OLs exposed to FGF-2, FGF-9, or FGF-18 are plotted as percentage of untreated $0 \mathrm{Ls}$. Increases in $0 \mathrm{~L}$ area induced by FGF-2, FGF-9, and FGF-18 were prevented by $\alpha$ R2 or PD but not $\alpha$ R1. DMSO vehicle (Veh) was similar to control. C, Immunoblot analyses and quantification of $0 \mathrm{Ls}$ exposed to FGF-2 demonstrates that the downregulation of FGFR2 (Ca) and MOG (Cb) protein expression was prevented by $\alpha$ R1 and PD but not by $\alpha$ R2 or $\alpha$ R3. Insets, Representative immunoblots show the expression of FGFR2 (Ca) and MOG (Cb). Error bars represent SEM; $n=3-5$ independent experiments, each performed in triplicate.

OL progenitors via FGFR3. Furthermore, the lack of proliferative response via FGFR3 signaling in OL progenitors is consistent with normal proliferation of OL progenitors in FGFR3-deficient mice (Oh et al., 2003). Conversely, FGFR3-deficient mice undergo delayed myelination, an observation that appears to be paradoxical with the inhibitory role of the FGFR3/FGF-8 pair shown in the present study. This could be attributable to genetic redundancy, wherein other molecules compensate for the function of the missing gene. Alternatively, a specific response to a growth factor that is elicited by purified populations of cells in vitro may be altered in the more complex in vivo environment of multiple, interacting cell types and growth factors (McKinnon et al., 1990). For example, in vitro CNTF stimulates both OL maturation and survival (Mayer et al., 1994). In contrast, in CNTFnull mice, OL progenitor proliferation rather than differentiation and myelination was affected (Barres et al., 1996). Similarly, the response of OL progenitors in culture to FGF-2 is modified by the presence of astrocytes (Bögler et al., 1990; McKinnon et al., 1990). Thus, the "context of presentation" is a critical determinant in the ultimate biological response of a cell to a growth factor.

FGF-9 activates FGFR2 in mature OLs and leads to process and membrane growth without downregulating myelin proteins as seen for FGF-2. Because extension of cellular processes is es- sential for the myelination of axons by OLs, FGF-9/FGFR2 signaling may have relevance for myelination in vivo. Consistent with this, FGF-9 and FGFR2 are expressed in the white matter, including the active phase of myelination (Tagashira et al., 1995; Miyake et al., 1996; Nakamura et al., 1999; Bansal et al., 2003b). It is interesting to note that, although FGF-2 induces process elongation, it also downregulates the synthesis of myelin proteins, accompanied by loss of membranes. This suggests that process extension and myelin protein synthesis are not mutually regulated. A plausible mechanism for this is the simultaneous activation of both FGFR1 and FGFR2 by FGF-2, leading to the two different effects.

In summary, we propose that FGF-2, FGF-8, FGF-17, and FGF-18 may be important FGFs during early development of OL progenitors acting via FGFR1 and FGFR3, FGF-9 may be important later on during myelination acting via FGFR2, whereas activation of FGFR1 by FGF-2 may have deleterious effects (below).

\section{FGF-2 and OL/myelin pathology}

A number of studies have assessed the potential role of FGF-2 in brain pathology, based in many cases on increases in FGF-2 levels after CNS insult (Gomez-Pinilla et al., 1990; Frank and Ragel, 1995; Yoshimura et al., 2001). In demyelinating lesions such as in multiple sclerosis, high levels of FGF-2 are produced by reactive astrocytes and macrophages (GomezPinilla et al., 1992; Hinks and Franklin, 1999; Messersmith et al., 2000; Holley et al., 2003). Concomitantly, FGFR1, which is normally low or undetectable in adult white matter (Asai et al., 1993), begins to be expressed by glial cells in lesions (Logan et al., 1992). We demonstrated that application of FGF-2 to mature OLs in culture gives rise to a novel OL phenotype characterized by a downregulation of major myelin-specific proteins and loss of myelin-like membranes, increases in process length, and cell cycle reentry with no mitogenic activity (for review, see Bansal, 2002). The loss of membranes in vitro under these conditions is reproduced in vivo, in which injection of FGF-2 led to loss of myelin (Butt and Dinsdale, 2005). Here we have shown that downregulation of myelin proteins or loss of myelin membrane is mediated by signaling via FGFR1 (not FGFR2 or FGFR3), suggesting that FGFR1 is the receptor responsible for eliciting this apparently deleterious effect of FGF-2 on mature OLs. An abnormal cell cycle reentry in mature OLs exposed to FGF-2 is also attributable to FGFR1 signaling that may eventually induce cell death via apoptosis (Muir and Compston, 1996). Therefore, we propose that localized increases in the level of FGF-2 at sites of demyelination may cause an aggravation of pathological responses via FGFR1 signaling as seen in culture. In contrast, a presumed positive effect of process growth is mediated via activation of FGFR2. Overall, these studies clarify mechanisms for the pleiotrophic effects of FGF-2 on mature OLs and help to 


\section{OL Progenitor}
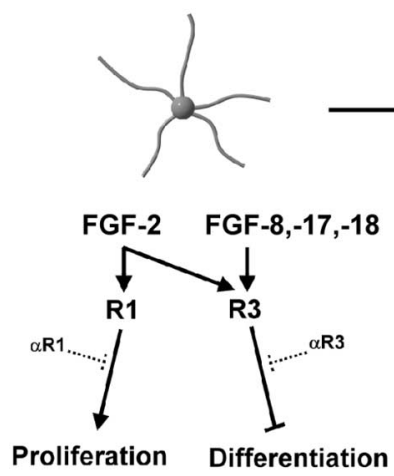
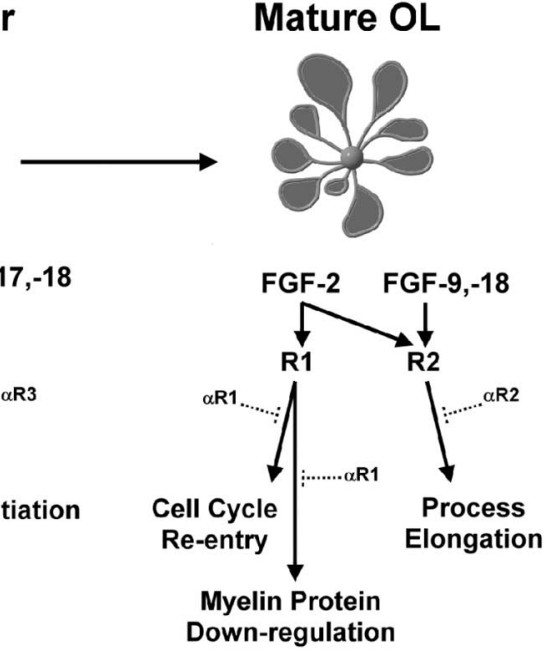

Figure 8. FGF/FGFR signaling pairs are associated with specific responses during oligodendrocyte development. Left, $0 \mathrm{~L}$ progenitors predominantly express FGFR1 and FGFR3. Activation of FGFR1 (R1) by FGF-2 induces their proliferation and concurrent suppression of differentiation. The selective activation of FGFR3 (R3) by FGF-8 (and related subfamily members FGF-17 and FGF-18) inhibits differentiation. Right, Differentiated OLs no longer express FGFR3 but upregulate the expression of FGFR2 and continue to express FGFR1. Specific activation of FGFR2 (R2) by FGF-9 stimulates process elongation. However, exposure of differentiated OLs to FGF- 2 , in addition to stimulating process elongation via FGFR2, also leads to the downregulation of myelin proteins and reentry into the cell cycle via FGFR1. These conclusions are based on a combination of specific FGF ligand presentation, blocking antibodies (dotted lines), and analysis of regulated expression of FGFRs.

identify potential targets for clinical intervention to FGFmediated pathology.

In summary, we propose a model in which ligand availability, coupled with changes in receptor expression, yield a changing repertoire of ligand-receptor complex formation and activation. As OLs progress through the developmental lineage, this leads to the differential responses to FGF stimulation that contribute critically to the regulation of OL differentiation. Finally, certain responses induced by FGF-2 may be associated with myelin pathology.

\section{References}

Arman E, Haffner-Krausz R, Chen Y, Heath JK, Lonai P (1998) Targeted disruption of fibroblast growth factor (FGF) receptor 2 suggests a role for FGF signaling in pregastrulation mammalian development. Proc Natl Acad Sci USA 95:5082-5087.

Asai T, Wanaka A, Kato H, Masana Y, Seo M, Tohyama M (1993) Differential expression of two members of FGF receptor gene family, FGFR-1 and FGFR-2 mRNA, in the adult rat central nervous system. Mol Brain Res $17: 174-178$.

Bansal R (2002) Fibroblast growth factors and their receptors in oligodendrocyte development: implications for demyelination and remyelination. Dev Neurosci 46:24-35.

Bansal R, Pfeiffer SE (1994) Inhibition of protein and lipid sulfation in oligodendrocytes blocks biological responses to FGF-2 and retards cytoarchitectural maturation, but not developmental lineage progression. Dev Biol 162:511-524.

Bansal R, Pfeiffer SE (1997) FGF-2 converts mature oligodendrocytes to a novel phenotype. J Neurosci Res 50:215-228.

Bansal R, Kumar M, Murray K, Morrison RS, Pfeiffer SE (1996) Regulation of FGF receptors in the oligodendrocyte lineage. Mol Cell Neurosci 7:263-275.

Bansal R, Magge S, Winkler S (2003a) Specific inhibitor of FGF receptor signaling: FGF-2-mediated effects on proliferation, differentiation, and MAPK activation are inhibited by PD173074 in oligodendrocyte-lineage cells. J Neurosci Res 74:486-493.

Bansal R, Lakhina V, Remedios R, Tole S (2003b) Expression of FGF recep- tors 1, 2, 3 in the embryonic and postnatal mouse brain compared with Pdgfralpha, Olig2 and Plp/dm20: implications for oligodendrocyte development. Dev Neurosci 25:83-95.

Baron W, Metz B, Bansal R, Hoekstra D, de Vries H (2000) PDGF and FGF-2 signaling in oligodendrocyte progenitor cells: regulation of proliferation and differentiation by multiple intracellular signaling pathways. Mol Cell Neurosci 15:314-329.

Barres BA, Burne JF, Holtmann B, Thoenen H, Sendtner M, Raff MC (1996) Ciliary neurotrophic factor enhances the rate of oligodendrocyte generation. Mol Cell Neurosci 8:146-156.

Bögler O, Wren D, Barnett SC, Land H, Noble M (1990) Cooperation between two growth factors promotes extended self-renewal and inhibits differentiation of oligodendrocyte-type-2 astrocyte (O-2A) progenitor cells. Proc Natl Acad Sci USA 87:6368-6372.

Butt AM, Dinsdale J (2005) Fibroblast growth factor 2 induces loss of adult oligodendrocytes and myelin in vivo. Exp Neurol 192:125-133.

Choi DY, Toledo-Aral JJ, Lin HY, Ischenko I, Medina L, Safo P, Mandel G, Levinson SR, Halegoua S, Hayman MJ (2001) Fibroblast growth factor receptor 3 induces gene expression primarily through Ras-independent signal transduction pathways. J Biol Chem 276:5116-5122.

Deng CX, Wynshaw-Boris A, Shen MM, Daugherty C, Ornitz DM, Leder P (1994) Murine FGFR-1 is required for early postimplantation growth and axial organization. Genes Dev 8:3045-3057.

Ford-Perriss M, Abud H, Murphy M (2001) Fibroblast growth factors in the developing central nervous system. Clin Exp Pharmacol Physiol 28:493-503.

Frank E, Ragel B (1995) Cortical basic fibroblast factor expression after head injury: preliminary results. Neurol Res 17:129-131.

Fressinaud C, Vallet JM, Labourdette G (1995) Basic fibroblast growth factor down-regulates myelin basic protein gene expression and alters myelin compaction of mature oligodendrocytes in vitro. J Neurosci Res 40:285-293.

Garel S, Huffman KJ, Rubenstein JL (2003) Molecular regionalization of the neocortex is disrupted in Fgf8 hypomorphic mutants. Development 130:1903-1914.

Gomez-Pinilla F, Cummings BJ, Cotman CW (1990) Induction of basic fibroblast growth factor in Alzheimer's disease pathology. NeuroReport 1:211-214.

Gomez-Pinilla F, Lee JWK, Cotman CW (1992) Basic FGF in adult rat brain: cellular distribution and response to entorhinal lesion and fimbria-bornix transection. J Neurosci 12:345-355.

Grinspan JB, Stern JL, Franceschini B, Pleasure D (1993) Trophic effect of basic fibroblast growth factor (bFGF) on differentiatied oligodendroglia: a mechanism for regeneration of the oligodendroglial lineage. J Neurosci Res 36:672-690.

Hasegawa H, Ashigaki S, Takamatsu M, Suzuki-Migishima R, Ohbayashi N, Itoh N, Takada S, Tanabe Y (2004) Laminar patterning in the developing neocortex by temporally coordinated fibroblast growth factor signaling. J Neurosci 24:8711-8719.

Hebert JM, Lin M, Partanen J, Rossant J, McConnell SK (2003) FGF signaling through FGFR1 is required for olfactory bulb morphogenesis. Development 130:1101-1111.

Hecht D, Zimmerman N, Bedford M, Avivi A, Yayon A (1995) Identification of fibroblast growth factor 9 (FGF9) as a high affinity, heparin dependent ligand for FGF receptors 3 and 2 but not for FGF receptors 1 and 4. Growth Factors 12:223-233.

Hinks GL, Franklin RJM (1999) Distinctive patterns of PDGF-A, FGF-2, IFG-1, and TGF- $\beta 1$ gene expression during remyelination of experimentally-induced spinal cord demyelination. Mol Cell Neurosci 14:153-168.

Holley JE, Gveric D, Newcombe J, Cuzner ML, Gutowski NJ (2003) Astrocyte characterization in the multiple sclerosis glial scar. Neuropathol Appl Neurobiol 29:434-444.

Itoh N, Ornitz DM (2004) Evolution of the Fgf and Fgfr gene families. Trends Genet 20:563-569.

Logan A, Frautschy SA, Gonzalez A-M, Baird A (1992) A time course for the focal elevation of synthesis of basic fibroblast growth factor and one of its high-affinity receptors (flg) following a localized cortical brain injury. J Neurosci 12:3828-3837.

Mayer M, Bhakoo K, Noble M (1994) Ciliary neurotrophic factor and leukemia inhibitory factor promote the generation, maturation and survival of oligodendrocytes in vitro. Development 120:143-153. 
McKinnon RD, Matsui T, Dubois-Dalcq M, Aaronson SA (1990) FGF modulates the PDGF-driven pathway of oligodendrocyte development. Neuron 5:603-614.

Messersmith DJ, Murtie JC, Le TQ, Frost EE, Armstrong RC (2000) Fibroblast growth factor 2 (FGF2) and FGF receptor expression in an experimental demyelinating disease with extensive remyelination. J Neurosci Res 62:241-256.

Miki T, Bottaro DP, Fleming TP, Smith CL, Burgess WH, Chan AM, Aaronson SA (1992) Determination of ligand-binding specificity by alternative splicing: two distinct growth factor receptors encoded by a single gene. Proc Natl Acad Sci USA 89:246-250.

Miller RH (2002) Regulation of oligodendrocyte development in the vertebrate CNS. Prog Neurobiol 67:451-467.

Miyake A, Hattori Y, Ohta M, Itoh N (1996) Rat oligodendrocytes and astrocytes preferentially express fibroblast growth factor receptor-2 and -3 mRNAs. J Neurosci Res 45:534-541.

Muir DA, Compston DA (1996) Growth factor stimulation triggers apoptotic cell death in mature oligodendrocytes. J Neurosci Res 44:1-11.

Nakamura S, Todo T, Motoi Y, Haga S, Aizawa T, Ueki A, Ikeda K (1999) Glial expression of fibroblast growth factor-9 in rat central nervous system. Glia 28:53-65.

Oh Y, Denninger A, Colvin JS, Vyas A, Tole S, Ornitz DM, Bansal R (2003) Fibroblast growth factor receptor-3 signaling regulates the onset of oligodendrocyte terminal differentiation. J Neurosci 23:883-894.

Ornitz DM, Leder P (1992) Ligand specificity and heparin dependence of fibroblast growth factor receptors 1 and 3. J Biol Chem 23:16305-16311.

Ornitz DM, Xu J, Colvin JS, McEwen DG, MacArthur CA, Coulier F, Gao G, Goldfarb M (1996) Receptor specificity of the fibroblast growth factor family. J Biol Chem 271:15292-15297.

Pfeiffer SE, Warrington AE, Bansal R (1993) The oligodendrocyte and its many cellular processes. Trends Cell Biol 3:191-197.

Rauchenberger R, Borges E, Thomassen-Wolf E, Rom E, Adar R, Yaniv Y, Malka M, Chumakov I, Kotzer S, Resnitzky D, Knappik A, Reiffert S, Prassler J, Jury K, Waldherr D, Bauer S, Kretzschmar T, Yayon A, Rothe C (2003) Human combinatorial Fab library yielding specific and functional antibodies against the human fibroblast growth factor receptor 3 . J Biol Chem 278:38194-38205.

Shaoul E, Reich-Slotky R, Berman B, Ron D (1995) Fibroblast growth factor receptors display both common and distinct signaling pathways. Oncogene 10:1553-1561.
Storm EE, Rubenstein JL, Martin GR (2003) Dosage of Fgf8 determines whether cell survival is positively or negatively regulated in the developing forebrain. Proc Natl Acad Sci USA 100:1757-1762.

Tagashira S, Ozaki K, Ohta M, Itoh N (1995) Localization of fibroblat growth factor-9 mRNA in the rat brain. Mol Brain Res 30:233-241.

Tanaka A, Kamiakito T, Hakamata Y, Fujii A, Kuriki K, Fukayama M (2001) Extensive neuronal localization and neurotrophic function of fibroblast growth factor 8 in the nervous system. Brain Res 912:105-115.

Turnbull J, Powell A, Guimond S (2001) Heparan sulfate: decoding a dynamic multifunctional cell regulator. Trends Cell Biol 11:75-82.

Wang J, Gao G, Goldfarb M (1994) Fibroblast growth factor receptors have different signaling and mitogenic potentials. Mol Cell Biol 1:181-188.

Wang J-K, Goldfarb M (1997) Amino acid residues which distinguish the mitogenic potentials of two FGF receptors. Oncogene 14:1767-1778.

Warrington AE, Barbarese E, Pfeiffer SE (1993) Differential myelinogenic capacity of specific developmental stages of the oligodendrocyte lineage upon transplantation into hypomyelinating hosts. J Neurosci Res 34:1-13.

Winkler S, Stahl RC, Carey DJ, Bansal R (2002) Syndecan-3 and perlecan are differentially expressed by progenitors and mature oligodendrocytes and accumulate in the extracellular matrix. J Neurosci Res 69:477-487.

Xu J, Lawshe A, MacArthur CA, Ornitz DM (1999) Genomic structure, mapping, activity and expression of fibroblast growth factor 17. Mech Dev 83:165-178.

Xu J, Liu Z, Ornitz DM (2000) Temporal and spatial gradients of Fgf8 and Fgf17 regulate proliferation and differentiation of midline cerebellar structures. Development 127:1833-1843.

Yayon A, Klagsbrun M, Esko JD, Leder P, Ornitz DM (1991) Cell surface, heparin-like molecules are required for binding of basic fibroblast growth factor to its high affinity receptor. Cell 64:841-848.

Yayon A, Zimmer Y, Shen GH, Avivi A, Yarden Y, Givol D (1992) A confined variable region confers ligand specificity on fibroblast growth factor receptors: implications for the origin of the immunoglobulin fold. EMBO J 11:1885-1890.

Yoshimura S, Takagi Y, Harada J, Teramoto T, Thomas SS, Waeber C, Bakowska JC, Breakefield XO, Moskowitz MA (2001) FGF-2 regulation of neurogenesis in adult hippocampus after brain injury. Proc Natl Acad Sci USA 98:5874-5879. 